\title{
OPEN
}

\section{Regional Lymphatic Inclusion in Orthotopic Hindlimb Transplantation: Establishment and Assessment of Feasibility in a Rodent Model}

\author{
loana Lese, MD, ${ }^{1,2}$ Franck M. Leclère, PhD, ${ }^{1}$ Thusitha Gayanayake, PhD, ${ }^{2}$ Adriano Taddeo, PhD, ${ }^{2}$ \\ Jonathan I. Leckenby, PhD, ${ }^{1,2}$ Yara Banz, PhD, ${ }^{3}$ Mihai A. Constantinescu, PhD, ${ }^{1,2}$ Esther Vögelin, PhD, ${ }^{1,2}$ \\ and Radu Olariu, MD ${ }^{1,2}$
}

\begin{abstract}
Background. The lymphatic system may play an important role in local immunomodulation in vascularized composite allotransplantation (VCA). Currently, there is no standardized VCA model that includes the regional draining lymphatic tissue. The aim of this study was to develop a rapid and efficient orthotopic hindlimb transplantation model in rats that included the draining lymphatic basin to permit further evaluation of the lymphatic system's role in VCA. Methods. Thirty transplantations from Brown Norway rats to Lewis rats were performed. To include the regional lymphatic tissue, the superficial epigastric vessels were preserved to allow retrieval of the corresponding inguinal lymph nodes, including the inguinal fat pad, with the hindlimb. A cuff technique was used for the vein, whereas the conventional microsurgical technique was used for the arterial anastomosis. Vascular patency was confirmed through laser Doppler analysis at postoperative day 1 and histological analysis after euthanasia. Results. The presence and vascularization of the inguinal lymph nodes were verified with indocyanine green lymphoscintigraphy at the time of transplantation. Mean total ischemia time was $69 \pm 24$ minutes, and mean recipient operation time was $80 \pm 19$ minutes. Overall transplant survival rate was 93.3\%. Laser Doppler analysis showed vascular (technical) success, indocyanine green lymphoscintigraphy confirmed the presence of lymph nodes and the histological analysis revealed patent anastomoses. Conclusions. We successfully developed an experimental orthotopic hindlimb transplantation model in rats that includes the draining inguinal lymphatic basin, which is an important asset in further research on lymphatic tissue and its role in VCA.
\end{abstract}

(Transplantation Direct 2020;6: e592; doi: 10.1097/TXD.0000000000001044. Published online 12 August, 2020.)

\section{INTRODUCTION}

Vascularized composite allotransplantation (VCA) is the process of transplanting tissue composed of several different subtypes, including bone, muscle, tendons and skin. Clinically, this is implemented in patients requiring reconstruction after upper extremity amputation or massive facial tissue loss in the form of hand or face transplantation. Even though the results of these reconstructive transplantations represent a unique "like with

\footnotetext{
Received 31 January 2020. Revision received 23 June 2020.

Accepted 24 June 2020.

Department of Plastic and Hand Surgery, Inselspital, Bern University Hospital, University of Bern Freiburgstrasse, Bern, Switzerland.

${ }^{2}$ Department for Biomedical Research, University of Bern, Bern, Switzerland. ${ }^{3}$ Institute of Pathology, University of Bern, Bern, Switzerland.

The authors declare no funding or conflicts of interest.

I.L. participated in the performance of the research and writing of the article. F.M.L. participated in the performance of the research and the review of the article. T.G. participated in the performance of the research. A.T. and J.I.L. participated in the performance of the research and review of the article. Y.B. participated in the performance of the histological analysis and the review of the article. M.A.C., E.V., and R.O. participated in the research design and review of the final version of the article.
}

like" tissue reconstruction, the treatment is not without disadvantages. To prevent rejection, patients are currently treated with life-long immunosuppression regimes that are associated with complications: patients are at higher risk of developing infections, malignancies, and renal failure. ${ }^{1}$ To date, $>100$ hand or upper extremity transplantation procedures have been performed worldwide. ${ }^{2}$ The main problems, beside acute rejection, are the longterm side effects of immunosuppressive therapy, ${ }^{2,3}$ and, consequently, there is a strong incentive to reduce the necessary immunosuppression and with it the unwanted side effects. Preclinical studies provide an important

Correspondence: Ioana Lese, MD, Department of Plastic and Hand Surgery, Inselspital, Bern University Hospital, University of Bern Freiburgstrasse, Lindenrain St, nr 1, Freiburgstrasse 4, 3010 Bern, Switzerland. (ioana.lese@ gmail.com)

Copyright (c) 2020 The Author(s). Transplantation Direct. Published by Wolters Kluwer Health, Inc. This is an open-access article distributed under the terms of the Creative Commons Attribution-Non Commercial-No Derivatives License 4.0 (CCBY-NC-ND), where it is permissible to download and share the work provided it is properly cited. The work cannot be changed in any way or used commercially without permission from the journal.

ISSN: 2373-8731

DOI: 10.1097/TXD.0000000000001044 
research platform to test new therapeutic modalities for minimization of immunosuppression and induction of immunological tolerance. ${ }^{4,5}$ More specifically, induction of immunologic tolerance of the tissue transplants would eliminate the need for such immunosuppression preventing, at the same time, the incidence of acute rejection episodes and the development of chronic rejection. However, the mechanisms for induction and maintenance of donor-specific tolerance are still incompletely understood and have yet not been translated to clinical practice. Recent studies show that a favorable avenue for immunomodulation is through the manipulation of the lymphatic network. ${ }^{6}$ Traditionally, the lymphatic system has been regarded as a passive drainage system for the regulation of fluid balance, lipid metabolism and immune cell trafficking to lymph nodes. However, recent data have challenged this view. There is mounting evidence suggesting that the lymphatic system plays an active role in modulating inflammation, autoimmune disease and organ immune-rejection processes. ${ }^{6}$ While on the one hand, the lymphatic system is thought to harm the allografts, other studies have shown that lymph node stromal cells and lymphatic endothelial cells may promote tolerance. ${ }^{7-9}$ The role of lymphatics and lymph nodes in VCA has been poorly investigated, and the available research models have not been designed to address the role of the draining lymphatic system in the immunological response following VCA.

Our aim was to develop a simple and efficient orthotopic hindlimb transplantation model in rats that includes the draining lymphatic basin. A technique that can include or discard regional lymphatic tissue in VCA would allow for more detailed analysis of the role the donor lymphatic system has in graft rejection. We describe our experience in developing a new model of rat hindlimb transplantation including its draining vascularized lymph nodes.

\section{MATERIALS AND METHODS}

\section{Animals}

Fifteen Brown Norway and 30 Lewis rats (Charles River, Germany) weighing 250-300g were used for this study. The Brown Norway rats were used as donors (both hindlimbs), while the Lewis rats were the recipients. All the experimental procedures were approved by the Veterinary Office of the Canton Bern and the animals were treated according to the Animal Welfare Act and Ordinance of the Swiss Animal Welfare Legislation during the entire experiment. Rats were housed in specific pathogen-free conditions with standard laboratory food and water ad libitum throughout the entire observation period.

\section{Surgical Procedure}

All rats received preemptive analgesia with buprenorphine $(50 \mu \mathrm{g} / \mathrm{kg})$ subcutaneously 30 minutes preoperatively. Operations were performed under continuous inhalation anesthesia. Isoflurane $5 \%$ with oxygen $(1 \mathrm{~L} / \mathrm{min})$ was used for the induction of anesthesia $(2-3 \mathrm{~min})$ in an induction chamber. Subsequently, the rats were placed on maintenance anesthesia at $1 \%-1.5 \%$ isoflurane with $0.6 \mathrm{~L} / \mathrm{min}$ oxygen. All rats were maintained at a normal body temperature using thermal pads and treated with ophthalmic ointment to both eyes to prevent desiccation. After procuring the hindlimb, the rats from the donor group were sacrificed by injecting $150 \mu \mathrm{g} / \mathrm{kg}$ pentobarbital intraperitoneally.

The surgical procedure was performed in a two-surgeon model, as previously described. ${ }^{10}$ The "first" surgeon prepared the hindlimbs from the first Brown Norway donor and placed the grafts under cold ischemia, while the "second" surgeon simultaneously prepared one side of the first recipient Lewis rat. Upon completion, the second surgeon immediately started to perform the transplantation. While this has been undertaken, the "first" surgeon retrieved the second donor hindlimb and euthanized the donor rat after this had been achieved. Now the "first" surgeon performed the corresponding hindlimb transplantation in exactly the same fashion. The durations of donor hindlimb retrieval, cold ischemia, warm ischemia and recipient surgery were recorded.

\section{Donor Hindlimb Retrieval}

The Brown Norway donor rats had heparin $(80 \mathrm{UI} / \mathrm{kg}$ ) given intravenously in the penile vein before the start of the operative procedure. The donor hindlimb was prepared by shaving and making a circumferential incision of the thigh at the inguinal crease level (Figure 1). After dissecting the groin flap based on the superficial epigastric vessels, the inguinal fat pad was procured to include the inguinal lymphatic tissue (Figure 2). The next step was to continue to prepare the donor limb for transplantation. The femoral nerve, artery and vein were isolated and divided sharply as close as possible to the inguinal ligament while taking care not to damage the superficial epigastric vessels; the femoral vessels were then prepared for the anastomosis with the recipient's vessels (artery outer

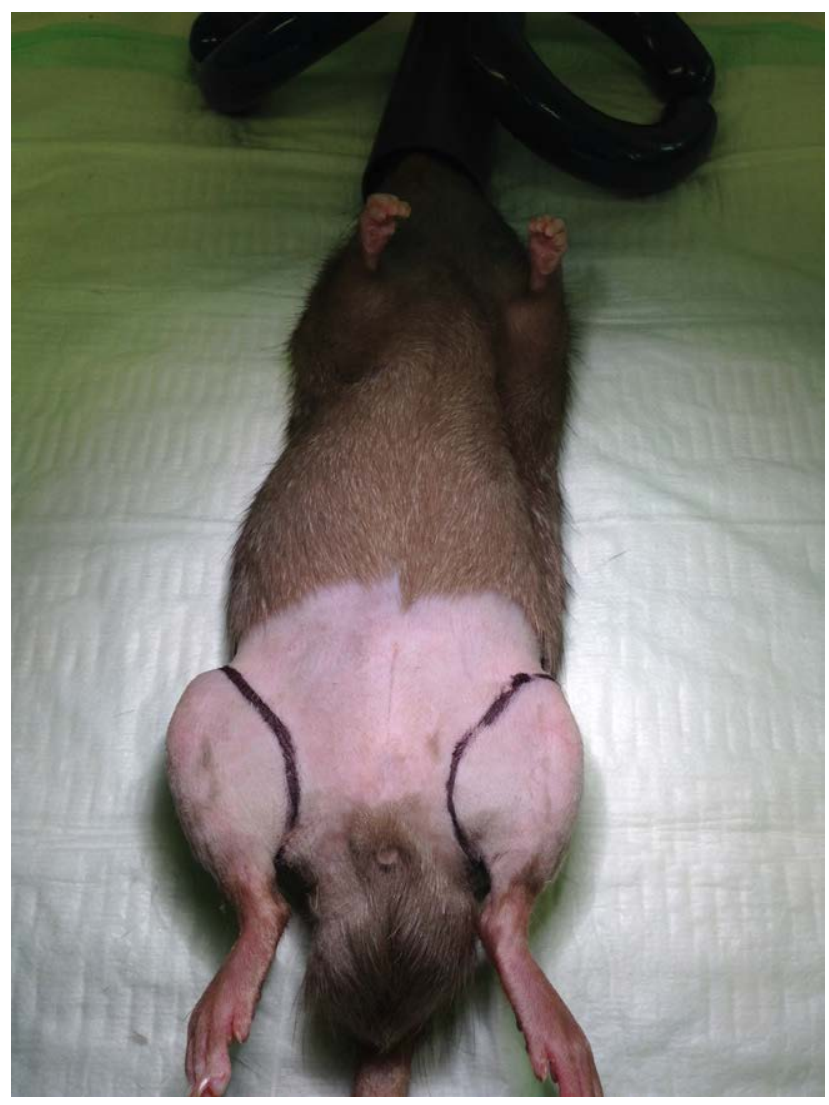

FIGURE 1. Incision markings of the donor hindlimbs. 


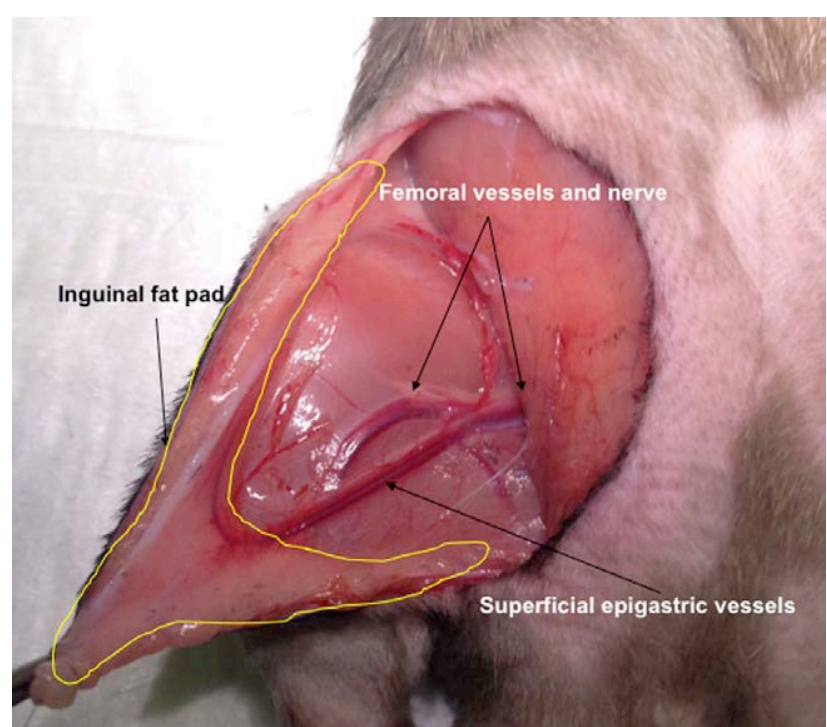

FIGURE 2. Inguinal fat pad supplied by the superficial epigastric vessels is included in the hindlimb to be transplanted.

diameter: $0.8 \pm 0.1 \mathrm{~mm}$; vein outer diameter: $1.1 \pm 0.1 \mathrm{~mm}$ ). The surrounding musculature was divided and the sciatic nerve was transected to completely expose the midportion of the femur. A transverse osteotomy was performed using a Liston bone-cutting forceps to complete the allograft retrieval. The limb was wrapped in saline-soaked gauze, inserted in a plastic bag, and then kept in an ice-bath. After procuring both limbs, the donor rat was euthanized and death was confirmed by performing bilateral thoracotomies.

\section{Recipient Hindlimb Preparation}

The ipsilateral recipient hindlimb was prepared in a similar fashion. The major difference was the level at which the artery, vein and nerves were sectioned: the femoral vessels and nerve were transected after application of a microvascular clamp just proximal to the superficial epigastric vessels' emergence, and the sciatic nerve was cut just proximal to its branching in the tibial, peroneal and sural nerves to facilitate microsurgical reconstruction by increasing the length of vasculature and nerve available.

\section{Allograft Transplantation}

Transplantation of the allograft began with the femoral osteosynthesis: an intramedullary rod was fashioned from an 18 -gauge needle with blunted ends. The medial muscle groups were approximated using interrupted 4-0 Vycril sutures to add stability to the limb during microsurgery. The venous anastomosis was performed using the "cuff" technique, similar to

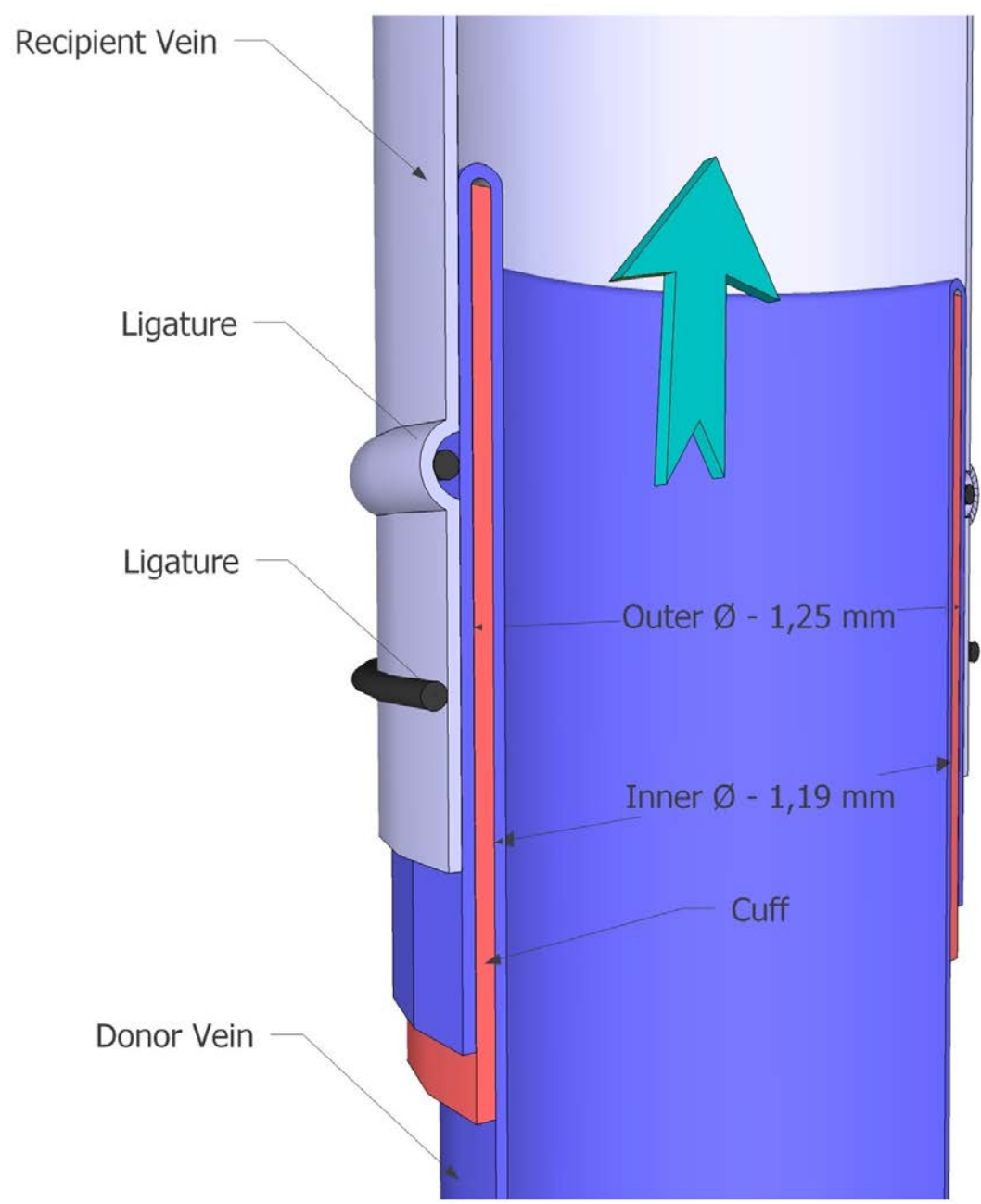

FIGURE 3. Schematic drawing demonstrating the venous anastomosis performed with the cuff technique. 
previous publications ${ }^{11}$ with Polyimide Medical Tubing 1410070 (Vention Medical Inc., Denver, United States; outer diameter: $1.25 \mathrm{~mm}$, wall thickness: $0.07 \mathrm{~mm}$, and inner diameter: $1.19 \mathrm{~mm})$.

Step 1: The femoral donor vein was pulled through a 2-3 mm length of the tubing.

Step 2: The vein was then everted over the body of the tube as a cuff and fixed circumferentially with a single loop of 9-0 Nylon ligature.

Step 3: The recipient vein was then pulled over the entire vein-tube-vein donor complex and secured with a single circumferential 9-0 Nylon ligature (Figure 3). The artery was anastomosed using interrupted 10-0 Nylon sutures (Figure 4) and the femoral and sciatic nerves were also coapted with interrupted 10-0 Nylon sutures. The remaining musculature was approximated accordingly, using interrupted 4-0 Vycril sutures. The skin was sutured in a continuous manner with 4-0 Vycril.

Before skin closure, buprenorphine $(50 \mu \mathrm{g} / \mathrm{kg})$ was administered subcutaneously as analgesia. All the recipients were kept on a heating pad for at least 1 hour after the operation. Analgesic treatment (buprenorphine $50 \mu \mathrm{g} / \mathrm{kg}$ s.c.) was administered every subsequent 12 hours until the second postoperative day or when the animals showed pain.

\section{Lymphography and Vascular Assessment}

Intraoperatively, before devascularization of the donor hindlimb, indocyanine green (ICG) lymphoscintigraphy was performed on the donor rat to ensure that the inguinal lymph nodes were included in the transplanted hindlimbs using the Visionsense Iridium System (Visionsense, Philadelphia, PA). $0.1 \mathrm{~mL}$ of ICG $5 \mathrm{mg} / \mathrm{mL}$ (ICG Pulsion, PULSION Medical Systems SE, Germany) was injected subcutaneously into the ipsilateral foot-pad of the limb to be transplanted (Figure 5). The Visionsense VS3 3DHD near-infrared camera (Visionsense Ltd., Petach Tikva, Israel) was then used to confirm the uptake of the fluorescent dye into the regional lymph nodes 5 minutes after injection. Upon confirmation of lymph node presence, $0.05 \mathrm{~mL}$ of ICG $5 \mathrm{mg} / \mathrm{mL}$ was injected in the penile vein and immediate assessment of the vascularization of the inguinal fat pad was performed with the Visionsense camera.

Laser Doppler imaging was performed on postoperative day (POD) 1 to confirm the vascularity of the transplanted hindlimb using the MoorLDI2-IR laser Doppler

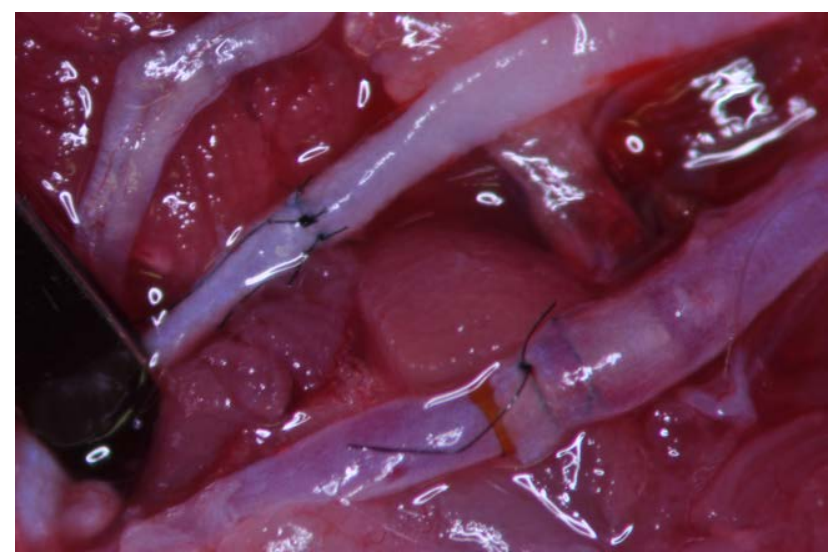

FIGURE 4. Arterial (left) and venous (right) anastomoses.
Imager (Moor Instruments Ltd., Axminster, Devon, United Kingdom).

\section{Postoperative Monitoring}

All recipient animals were monitored every 12 hours for the first 24 hours and then daily until the end of the experiments. No immunosuppression was administered. All animals with patent intraoperative anastomoses at the end of the experiment and confirmed vascularization by laser Doppler imaging on POD 1 (at least $24 \mathrm{~h}$ after surgery) were considered technically successful. Euthanasia was performed at POD 5 or when grade 3 rejection was recorded. Venous cuffs and inguinal fat pad tissues, with containing lymph nodes, were procured selectively and sent for histological analysis with hematoxylin and eosin staining.

\section{RESULTS}

All results are expressed as mean values $( \pm \mathrm{SE}$ mean $)$.

\section{Surgical Procedure}

The surgical procedure was straightforward, and no surgical protocol-related problems were revealed.

The mean donor operation time, including the retrieving of both limbs, was $33 \pm 8$ minutes. For the cold ischemia, the mean time calculated was $19 \pm 4$ minutes. The mean warm ischemia time was $59 \pm 17$ minutes, and the mean total

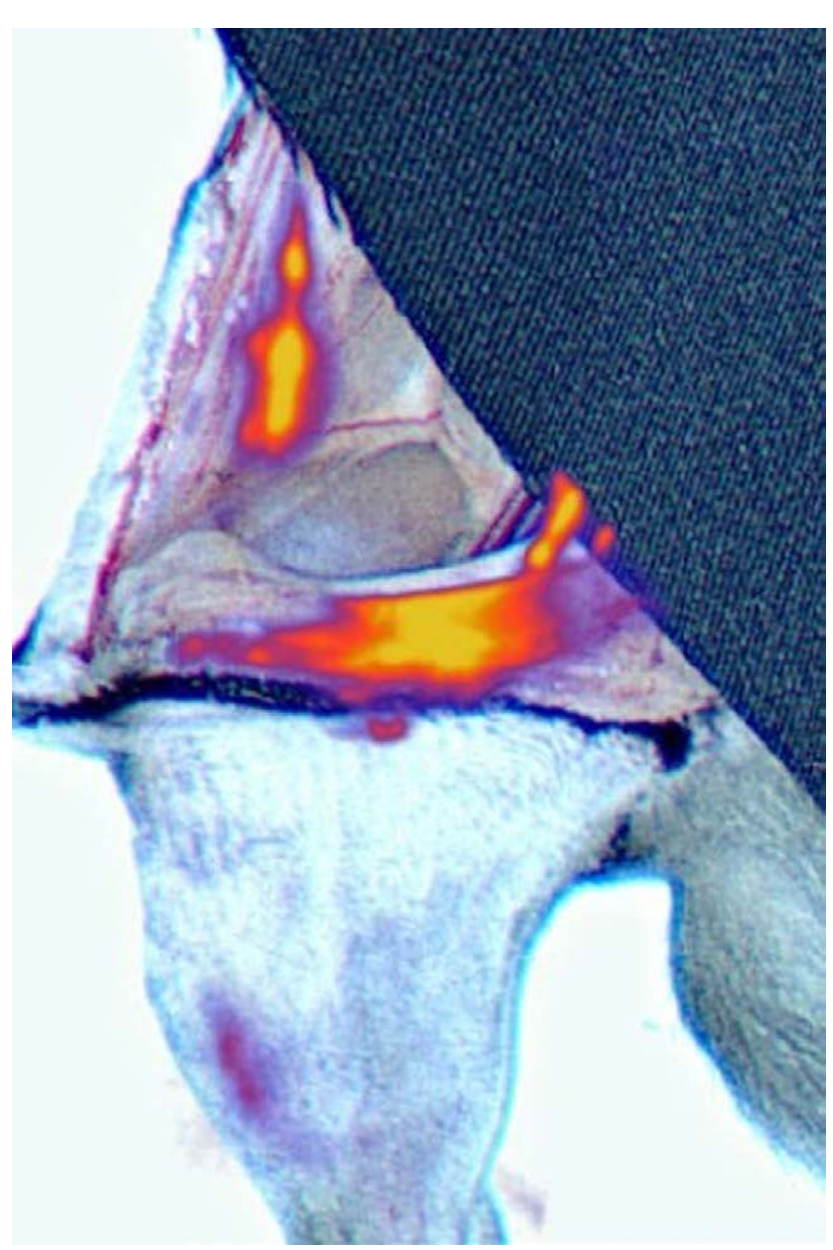

FIGURE 5. Inguinal lymph nodes are fluorescent after injecting indocyanine green in the foot fat pad. 
ischemia time was $69 \pm 24$ minutes. The recipient rats underwent surgery for $80 \pm 19$ minutes.

The overall immediate surgical transplant success rate was $93 \%$, with 2 nonsalvageable anastomotic failures occurring intraoperatively. The rats were euthanized while under anesthesia.

\section{Lymphography and Vascular Assessment}

Lymphography with ICG showed the presence of lymph nodes in the transplanted inguinal fat pad. Injection of ICG intravenously showed complete vascularization of the inguinal fat pat in the transplanted limb via the superficial epigastric vessels (Figure 6).

On POD 1, laser Doppler analysis showed vascular (technical) success with clear vascularization of the graft in $100 \%$ of the cases (Figure 7). There were no cases of bleeding, selfmutilation, perfusion, or anesthesia problems.

\section{Postoperative Monitoring}

A total of 28 rats $(93.3 \%)$ reached the endpoint of the experiment at POD 5. There were no postoperative complications. Out of the 28 rats, only 8 rats recorded a grade 1 rejection on POD 5 (erythema and edema of the skin), while the other animals did not show any signs of rejection.

The histological examination of the selectively retrieved venous cuffs showed patent anastomoses (Figure 8). The inguinal fat pads revealed inflammatory infiltrate (Figure 9), while the lymph nodes showed minimal reactive changes (Figure 10)

\section{DISCUSSION}

The benefits of rodent VCA models provided are clear, and the development of the rat hindlimb transplantation model was crucial in driving forward VCA research ${ }^{12}$; studies have been able to analyze ischemia-reperfusion injury, immunosuppressive therapy, acute and chronic rejection and tolerance induction. ${ }^{13-16}$ Brown Norway-to-Lewis hindlimb transplantation is a widely used model in VCA research because of the strong MHC mismatch and ease of clinical assessment of the allograft due to color difference.

The first orthotopic hindlimb transplantation of a rat was described by Shapiro and Cerra. ${ }^{17}$ Although the model was somewhat time-consuming, involving meticulous
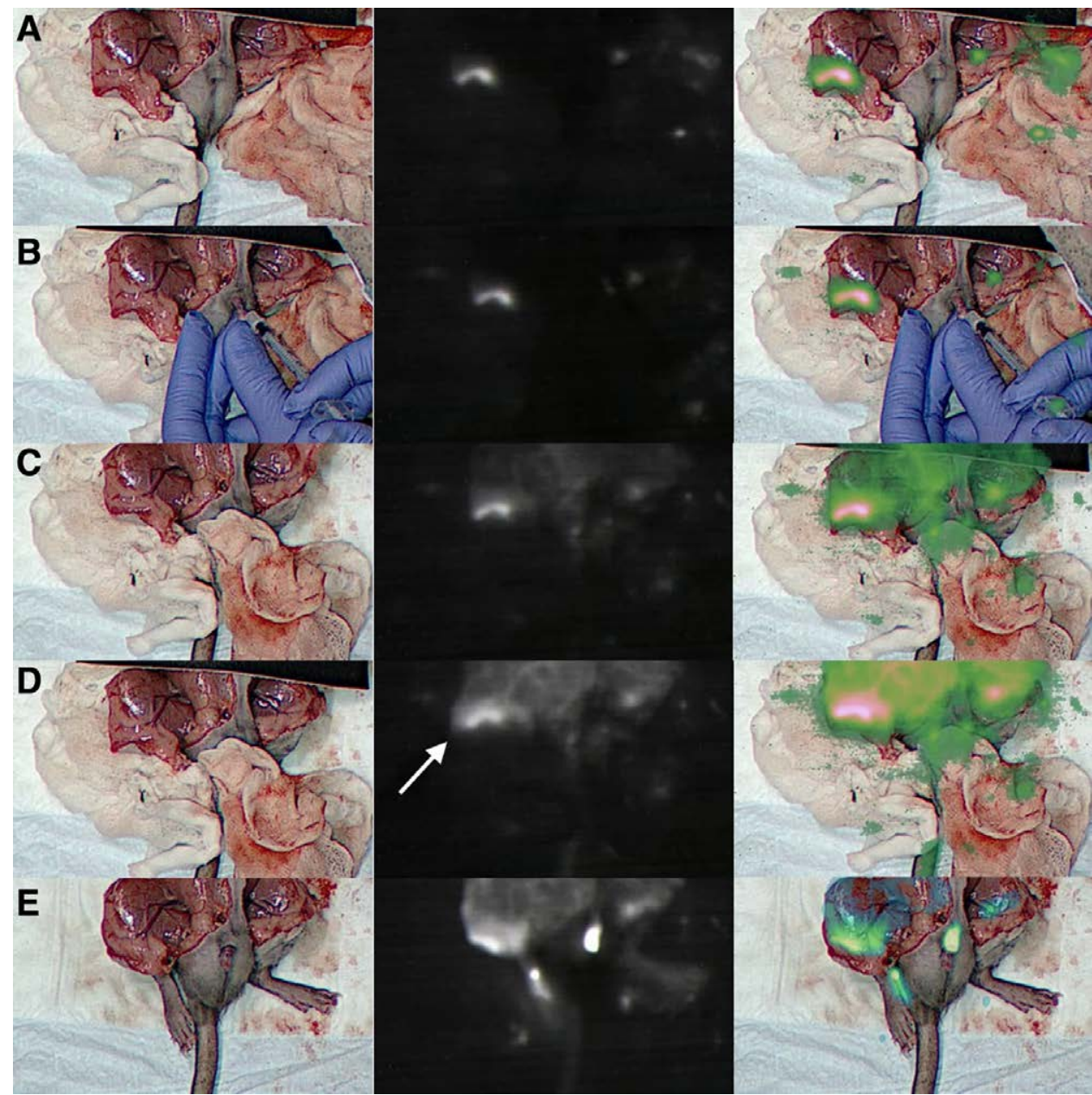

FIGURE 6. Inguinal lymph nodes and the fat pad are fluorescent after injection of ICG in the penile vein. The first column shows the native images (visual only), the second column shows the fluorescent images, whereas the last column depicts the fusion of fluorescent and visual images (overlay). A, Pre-intravenous injection of ICG. The lymph nodes can be seen fluorescent due to the ICG that was injected in the foot. B, Injection of ICG in the penile vein. C, The tissues are fluorescent a few s after intravenous injection of the ICG. D, The intensity of the fluorescence is higher at $1 \mathrm{~min}$ after injection, with complete visualization of the vascularisation of the fat pad (white arrow). E, Patent outflow of the ICG from the tissues, 7 min postinjection. ICG, indocyanine green. 


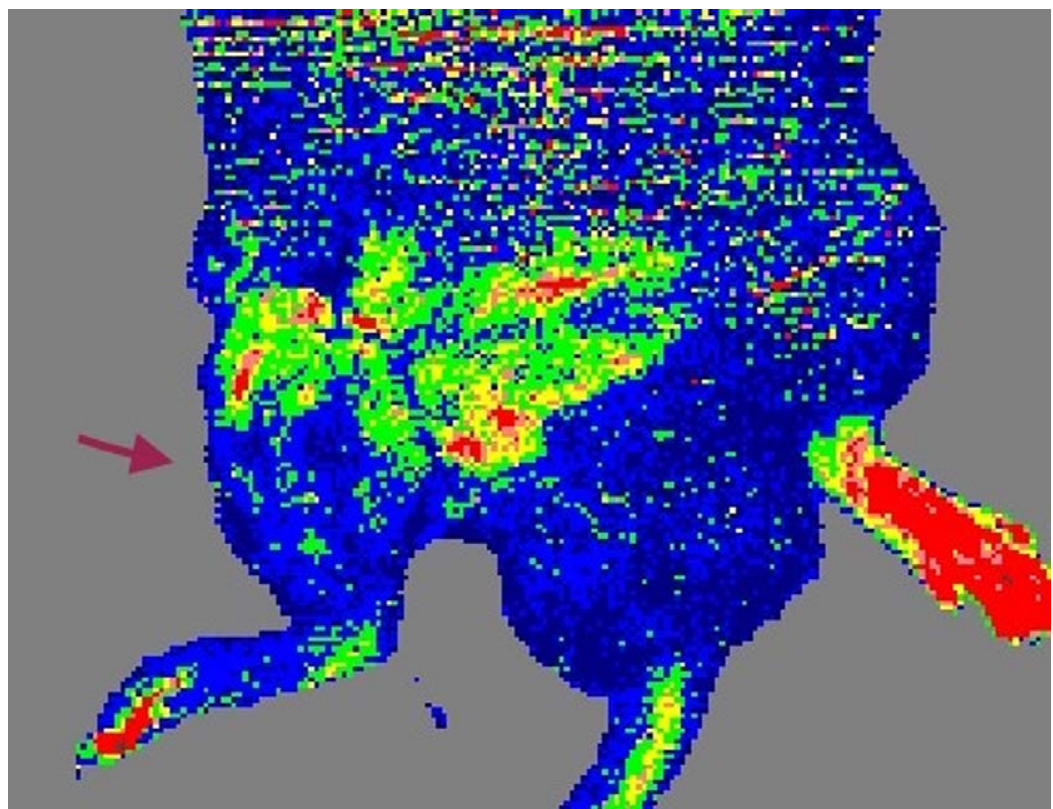

FIGURE 7. Laser Doppler analysis on POD 1 (the arrow indicates the transplanted hindlimb). POD 1, postoperative $d 1$.

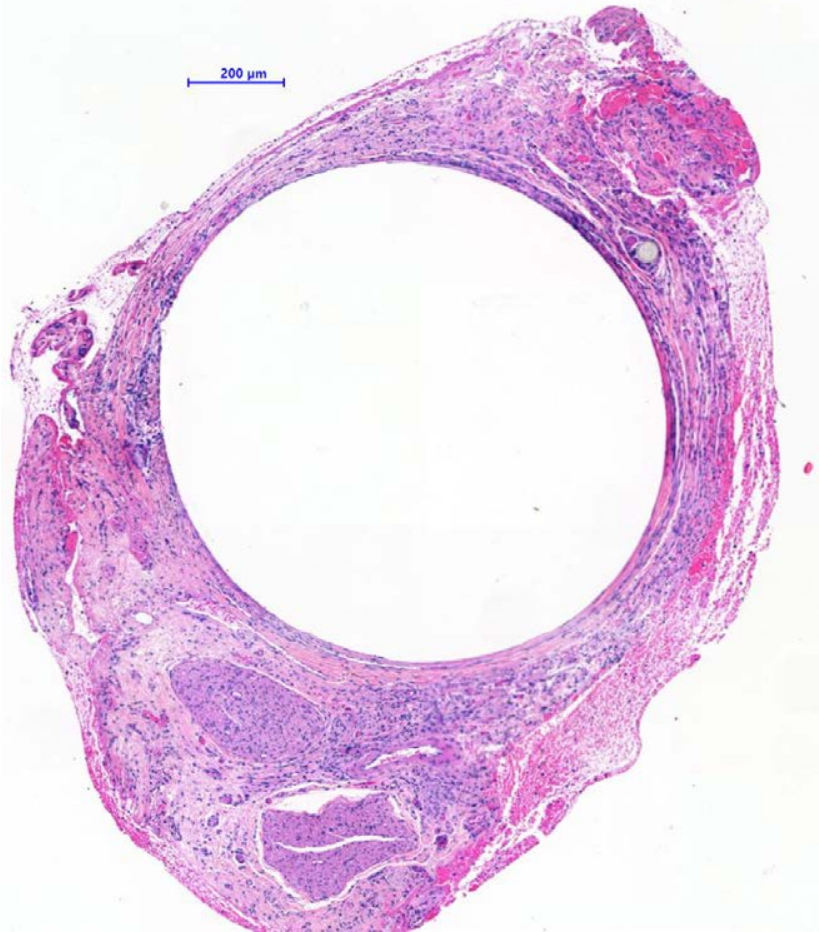

FIGURE 8. Hematoxylin and eosin stain of a vein at the point of anastomosis. The viable vessel shows minor unspecific inflammation and minimal fibrosis as well as some foreign body (suture) material.

reattachments of bone, muscle, nerve, and blood vessels, it was the cornerstone of reconstructive transplantation research. Since then, great effort has been made to improve the model for VCA. A well-known model, developed by Sucher et al, uses the cuff technique, where the vessel anastomoses are completed utilizing a polypropylene tube. ${ }^{11}$ Sacks et al introduced the concept of the dual surgeon technique to reduce operative time. ${ }^{10}$

In the model described above, the cuff technique is only used for the venous anastomosis. This is more expeditive and has an equivalent success rate compared with traditional techniques within our laboratory. Traditional interrupted sutures are still used for the artery as we find the muscular layer of the arterial wall difficult to evert over the tubing and we have seen a higher rate of intimal wall damage.

In the technique described, the warm, cold, and total ischemia times were comparable to literature. As expected, our ischemia times were less than traditional techniques and more than the complete cuff technique (arterial and venous) described by Sucher et al. ${ }^{11}$ In their study, $20 \pm 2$ and $25 \pm 2$ 
A

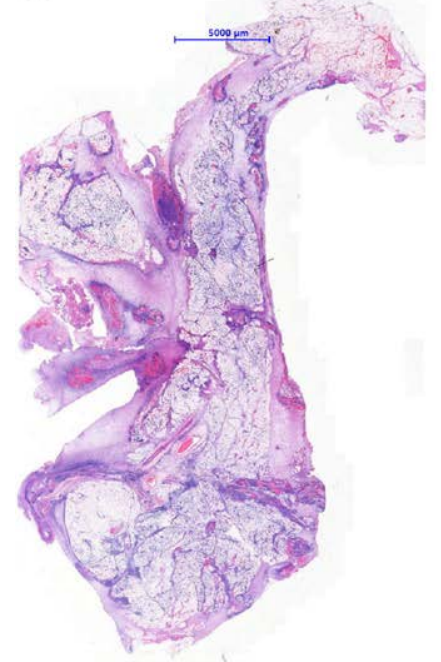

B

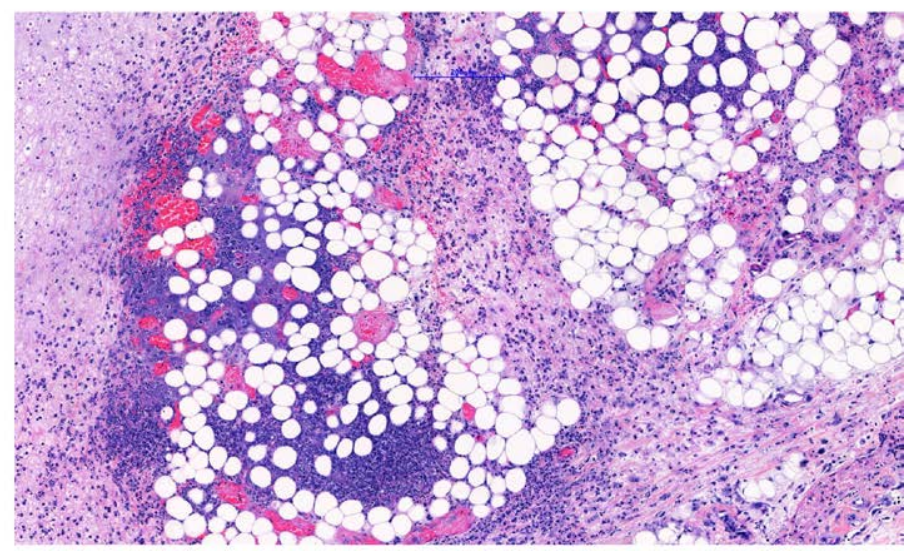

FIGURE 9. Hematoxylin and eosin stain of a fat pad, overview (A) and detail (B). The fat tissue shows areas of necrosis with corresponding inflammatory infiltrate, consisting mainly of neutrophil granulocytes and some (foamy) macrophages.

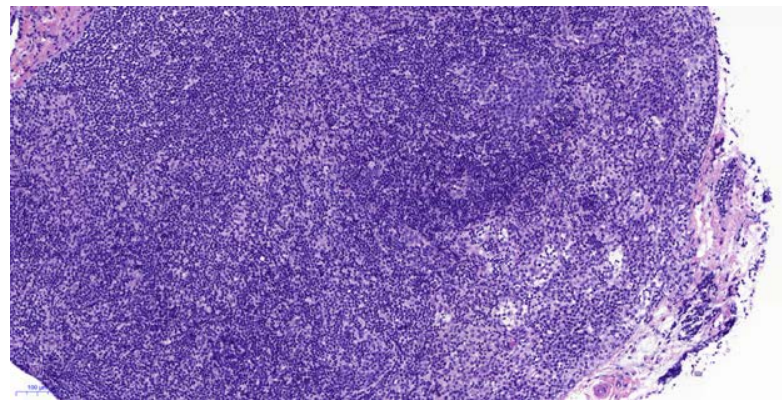

FIGURE 10. Hematoxylin and eosin stain of a representative inguinal lymph node (10x, scale bar shown). The lymph node shows a preserved architecture with some follicular hyperplasia (top right of image) and minimal reactive changes including interfollicular T-Zone expansion and some macrophage accumulation in the peripheral sinus. Clear-cut ischemic changes were not noted within the lymph node tissue, but some focal necrosis was observed in some cases in the perinodal fatty tissue (not shown here).

minutes, respectively, was the duration for each donor hindlimb operation, in comparison to $33.3 \pm 8.8$ minutes required in this study for the procuring of 2 hindlimbs with the overall operative time also reduced. ${ }^{10,11}$ The entire recipient operation was $80 \pm 19$ minutes, this value being in line with the results obtained by Sucher et al for the conventional and cuff technique, and less than Sacks et al and Ulusal et al ${ }^{10-12}$ (Table 1). We could, therefore, demonstrate that the rat hindlimb VCA model with inclusion of vascularized inguinal lymph nodes that we describe is from a technical point of view equivalent to the known models in terms of ischemia and operation time.

The histological samples collected selectively showed patent anastomoses and the presence of viable lymphatic tissue. We were able thus to develop a model that reliably includes the whole lymphatic drainage basin with the transplant in a vascularized manner. This is in line with growing interest in recent VCA research on the contributions the lymphatic system has in transplant rejection. ${ }^{8,9}$ Until recently, the prevailing view has been that the lymphatic circulation is primarily harmful to allografts: the increased lymphangiogenesis after organ transplantation enhances the delivery of antigenpresenting cells that carry allogenic antigens to the draining lymph nodes to provoke unwanted immune responses. ${ }^{7}$ Accordingly, lymphangiogenesis suppression improves the survival of experimentally transplanted pancreatic islet cells ${ }^{18}$ and cornea. ${ }^{19}$ Moreover, Baker et $\mathrm{al}^{20}$ and later Lakkis et $\mathrm{al}^{21}$ demonstrated that animals lacking secondary lymphoid organs were not able to reject vascularized organs or allogeneic skin grafts since no recipients were found for the newly developed lymphatic vessels. Studies have suggested that the lymphatic system and the associated lymph nodes can work bifunctionally, driving immunity versus tolerance according to demand. ${ }^{6,22}$ Recent studies suggest that lymphatic neoangiogenesis seems to be involved in the resolution of cellular rejection and the reduction of inflammation. ${ }^{8,9}$ However, there are no described experimental models in which all the draining

\section{TABLE 1.}

\section{Comparison of mean operative times between different techniques and models}

\begin{tabular}{|c|c|c|c|c|c|}
\hline Author & $\begin{array}{l}\text { Total ischemia } \\
\text { time (min) }\end{array}$ & $\begin{array}{l}\text { Cold ischemia } \\
\text { time (min) }\end{array}$ & $\begin{array}{l}\text { Warm ischemia } \\
\text { time (min) }\end{array}$ & $\begin{array}{l}\text { Donor operation } \\
\text { time (min) }\end{array}$ & $\begin{array}{c}\text { Recipient } \\
\text { operation time (min) }\end{array}$ \\
\hline Ulusal et al ${ }^{12}$ & 85 & - & - & - & 105 \\
\hline Sacks et al ${ }^{10}$ & 66 & - & - & $58^{a}$ & 105 \\
\hline Sucher et $\mathrm{al}^{11}$ (conventional technique) & - & 29 & 75 & 25 & 126 \\
\hline Sucher et al ${ }^{11}$ (cuff technique) & - & 27 & 32 & 20 & 51 \\
\hline Lymph node including hindlimb transplantation & 69 & 19 & 59 & $33^{a}$ & 80 \\
\hline
\end{tabular}

aTime for both donor hindlimbs. 
lymphatic tissues of an allograft are transplanted in a vascularized manner. Moreover, the presence of donor lymph nodes in the proximity of the recipient tissues could influence the lymphatic reconstitution process and might, therefore, differ from the lymphatic regeneration patterns already described in rat replantation models ${ }^{23}$ and rat allotransplantation models. ${ }^{14}$ The presence of vascularized lymph nodes could increase the amount of lymphangiogenic growth factors (eg, VEGF-C) and subsequently accelerate the formation of new lymphatic vessels that could drain the transplanted limb. Moreover, VEGF-C might also dampen, through promotion of neolymphangiogenesis, the inflammation present postoperatively or due to incipient rejection. ${ }^{24,25}$ The hereby described model opens up the possibility of a more detailed analysis of the role of vascularized lymph node co-transplantation on the complex and still not completely understood immunological processes responsible for rejection in VCA.

Therefore, we find that such a model would be an important addition to the VCA research armamentarium since in this case, the immune cells from the recipient blood would be first drained after having made contact with the donor antigens in donor-origin lymph nodes, therefore allowing for a unique immune interaction that might bring more insight into the various graft-host interactions.

\section{CONCLUSIONS}

This study has demonstrated that the regional inguinal lymphatic system can be successfully incorporated into a standardized rat hindlimb transplantation model. The cuff technique for venous anastomosis only has proved equivalent to other described techniques. This study shows the feasibility of a surgical technique that can allow lymphatic material to be transplanted or excluded in VCA studies, opening the door to further research into the impact lymphatics have on graft rejection.

\section{REFERENCES}

1. Schneeberger S, Ninkovic M, Gabl M, et al. First forearm transplantation: outcome at 3 years. Am J Transplant. 2007;7:1753-1762.

2. Shores JT, Brandacher G, Lee WP. Hand and upper extremity transplantation: an update of outcomes in the worldwide experience. Plast Reconstr Surg. 2015;135:351e-360e.

3. Petruzzo P, Lanzetta M, Dubernard J-M, et al. The international registry on hand and composite tissue transplantation. Transplantation. 2010;90:1590-1594.
4. Gajanayake T, Olariu R, Leclère FM, et al. A single localized dose of enzyme-responsive hydrogel improves long-term survival of a vascularized composite allograft. Sci Trans/ Med. 2014;6:249ra110.

5. Olariu R, Denoyelle J, Leclère FM, et al. Intra-graft injection of tacrolimus promotes survival of vascularized composite allotransplantation. J Surg Res. 2017;218:49-57.

6. Card CM, Yu SS, Swartz MA. Emerging roles of lymphatic endothelium in regulating adaptive immunity. J Clin Invest. 2014;124:943-952.

7. Hos D, Cursiefen C. Lymphatic vessels in the development of tissue and organ rejection. Adv Anat Emryol Cell Biol. 2014;214:119-141.

8. Cui Y, Liu K, Monzon-Medina ME, et al. Therapeutic lymphangiogenesis ameliorates established acute lung allograft rejection. J Clin Invest. 2015;125:4255-4268.

9. Ishii E, Shimizu A, Kuwahara N, et al. Lymphangiogenesis associated with acute cellular rejection in rat liver transplantation. Transplant Proc. 2010;42:4282-4285.

10. Sacks JM, Kuo Y-R, Horibe EK, et al. An optimized dual-surgeon simultaneous orthotopic hind-limb allotransplantation model in rats. J Reconstr Microsurg. 2012;28:69-75.

11. Sucher R, Oberhuber R, Rumberg G, et al. A rapid vascular anastomosis technique for hind-limb transplantation in rats. Plast Reconstr Surg. 2010;126:869-874.

12. Ulusal AE, Ulusal BG, Hung L-M, et al. Heterotopic hindlimb allotransplantation in rats: an alternative model for immunological research in composite-tissue allotransplantation. Microsurgery. 2005;25:410-414.

13. Brandacher G. The Science of Reconstructive Transplantation. New York, NY: Humana Press; 2015.

14. Buretta KJ, Brat GA, Christensen JM, et al. Near-infrared lymphography as a minimally invasive modality for imaging lymphatic reconstitution in a rat orthotopic hind limb transplantation model. Transpl Int. 2013;26:928-937.

15. Lanzetta M. Hand Transplantation. Italy: Springer; 2007.

16. Tai C, Goldenberg M, Schuster KM, et al. Composite tissue allotransplantation. J Invest Surg. 2003;16:193-201.

17. Shapiro RI, Cerra FB. A model for reimplantation and transplantation of a complex organ: the rat hind limb. J Surg Res. 1978;24:501-506.

18. Yin $\mathrm{N}$, Zhang $\mathrm{N}, \mathrm{Xu} \mathrm{J}$, et al. Targeting lymphangiogenesis after islet transplantation prolongs islet allograft survival. Transplantation. 2011;92:25-30.

19. Dietrich T, Bock F, Yuen D, et al. Cutting edge: lymphatic vessels, not blood vessels, primarily mediate immune rejections after transplantation. J Immunol. 2010;184:535-539.

20. Barker CF, Billingham RE. The role of afferent lymphatics in the rejection of skin homografts. J Exp Med. 1968;128:197-221.

21. Lakkis FG, Arakelov A, Konieczny BT, et al. Immunologic 'ignorance' of vascularized organ transplants in the absence of secondary lymphoid tissue. Nat Med. 2000;6:686-688.

22. Shields JD. Lymphatics: at the interface of immunity, tolerance, and tumor metastasis. Microcirculation. 2011;18:517-531.

23. Anthony JP, Foster RD, Price DC, et al. Lymphatic regeneration following microvascular limb replantation: a qualitative and quantitative animal study. J Reconstr Microsurg. 1997;13:327-330.

24. Gould DJ, Mehrara BJ, Neligan P, et al. Lymph node transplantation for the treatment of Iymphedema. J Surg Oncol. 2018;118:736-742.

25. Schwager S, Detmar M. Inflammation and lymphatic function. Front Immunol. 2019;10:308. 